\title{
Simo Säätelä
}

\section{Estetik kunskap och rationalitet ${ }^{\star}$}

Vid Statens Tekniska forskningscentral i Finland pågår sedan hösten 1987 projektet "Esteettisesti ja laadullisesti korkeatasoinen fyysinen ympäristō ja uudet suunnittelutekniikat" ["En estetiskt och kvalitativt högklassig fysisk miljö och de nya planeringsteknikerna"] (härefter ESSU). Projektet strävar att beakta de nya (datorströdda) planeringsteknikernas" 1 kvalitativa inverkan på planeringsresultatet (dvs. den bebyggda miljön), med speciell tonvikt vid estetisk kvalitet. Man måste alltså fråga sig vilka krav arkitetkturplaneringens este tiska dimension ställer på den använda planeringstekniken. Arkitekturen befinner ju sig på ett intressant sätt i ett område där "konstvärlden" och "vetenskapsvärlden" sas. överlappar varandra, vilket syns särskilt tydligt inom ESSU-projektet. Projektets målsättning leder därmed till vissa konstfilosofiskt intressanta problemställningar.

Inom ESSU-projektet har det framförts många olika sätt att betrakta den prototyp som man hoppas skall kröna arbetet. Skall vi tala om ett verktyg, en automatiserad arkitekt, en automatiserad kritiker, en "påminnare" som hjälper arkitekten att komma ihåg att beakta också de estetiska aspekterna, el.dyl.? Det konkreta målet tycks i så gott som samt-

1Jag förbigår här helt de tekniska aspekterna av projektet. "De nya planeringsteknikerna" är ett mycket omfattande begrepp, som innefattar CAD (Computer Aided Design) kombinerat med olika former av artificiell intelligens, expertsystem, hypermedia, visualiseringstekniker, machine-user interface, etc. 
liga fall innebära något slags implementeringar av s.k. expertsystem, dvs. dataprogram, som i bästa fall kan utföra vissa uppgifter som vanligen måste handhas av en mänslig expert. Expertsystemet bygger oftast på en "representation" av expertkunskapen i något slag av databas samt vissa regler för användningen av denna kunskap - regler som sas. beskriver expertens aktivitet. Expertsystem kan också innehålla s.k. artificiell intelligens (AI). Målsättningen innebär att estetiska och epistemologiska frågor inte helt och hållet kan hållas åtskilda inom ESSU-projektet.

Något, som ofta betraktas som en rent filosofisk fråga, dvs. frågan om det estetiska omdömets natur, blir därmed av stort praktiskt intresse, eftersom mycket just hänger på den form av "kunskap" som ingår i det estetiska omdömet - vad det grundar sig på, hur dess rationalitet kan konstrueras, etc. Detta betyder att olika syner på estetikens roll och status blir en central angelängenhet. En synvinkel som färgade projektets begynnelseskede var - hur absurt det än kan låta - idén om estetiken som "en vetenskap om det sköna". Estetikernas uppgift ansågs alltså vara att ge de nödvändiga reglerna för utvecklingen av något slags "estetiskt" expertsystem. Detta missförstånd, intressant som det i och för sig är, behöver knappast kommenteras vidare. Men trots att denna idé om estetikens roll inom projektet har kunnat förkastas, krävs fortfarande ett ställningstagande i vissa fundamentala frågor som gäller estetikens uppgift och natur. Dessa frågor rör sig i ett ständigt aktuellt problemfält inom både konst- och vetenskapsfilosofin: motsättningen mellan positivistiska och icke-positivistiska tankesätt.

Man kan säga att undersökningen av den "kunskapsform" som är relevant $i$ estetiska sammanhang samtidigt belyser den praxis inom vilken arkitekturen och planerarens verksamhet blir meningsfull. Av särskilt intresse blir då de frågor som gäller den "kunskapsrepresentation" som är möjlig i dessa sammanhang. På grund av den estetiska diskursens kommunikationsform och de svårigheter man stöter på i försöken att formulera något slag av estetiska regler, aktualiseras den omstridda frågan om sk. tyst kunskap. ${ }^{1}$ Då man talar om "tyst" (eller alterna-

IJag tänker inte här gå närmare in på detta problemområde. Den intresserade hänvisas til Burman \& Säätelä 1988. 
tivt "intransitiv") kunskap inom t.ex. arkitekturen vill man peka på vissa viktiga saker och samtidigt polemisera mot vissa sätt att se arkitekturens "kunskapsproblem". De saker man vill lägga vikt vid är å ena sidan den aspekt av yrkeskunskap eller praktiskt kunnande som ingår i arkitekturen. A andra sidan gäller frågan arkitekturens eller planeringens natur och vår förståelse av dessa aktiviteter. Båda aspekterna innebär vissa problem med tanke på den "kunskapsrepresentation" som är möjlig t.ex. med tanke på implementering av artificiell intelligens eller expertsystem. Jag skall här behandla bara den sistnämnda frågan.

Problemen tycks uppkomma genom att man i tekniska sammanhang och inom s.k. "kognitiv vetenskap" (cognitive science) har en tendens att vilja definiera begrepp som "kunskap", kunnande osv. genom de krav som datorimplementeringar, t.ex. i form av expertsystem, ställer på kunskapen, och inte tvärtom. Detta betyder att den mer eller mindre omedvetna positivistiskt färgade tradition som ligger bakom datautveckling kommer att inverka på synen vad kunskap är. Till denna tradition hör också den dominerande (logisk-positivistiska) vetenskapsfilosofiska synen, enligt vilken det borde vara möjligt att explicit uttrycka all genuin kunskap i form av en logisk kalkyl. Allt tal om någon form av "tyst" kunskap skulle alltså bara vara onödig mystifiering. Ur denna synvinkel är den kunskapsform vi har att göra med i estetiska sammanhang på något sätt bristfällig, eftersom den tycks lämna utrymme för suddiga och oartikulerade områden. Problemet gäller dock inte bara begreppens eventuella "suddighet" (fuzziness) och möjligheten att definiera den, utan dess rötter sträcker sig djupare, till uppfattningar om språket och dess förhållande till verkligheten. Man måste fråga sig, vad vi kan mena med en "fullständig förståelse" av ett visst områdes kunskap. Betyder detta även att kunskapen i fråga är restlöst artikulerbar i propositionell form?

Man kan identifiera två huvudsakliga problem i representationen av den kunskap som ār aktuell inom estetiska sammanhang: den estetiska diskursens kommunikationsform samt de estetiska begreppens "suddighet" (vilket betyder att deras mening ār kontextbunden så att den tycks variera från fall till fall, och att de inte kan definieras på ett entydigt sätt). Traditionellt har man kunnat se två lösningar på dessa problem: 
1) den estetiska diskursen är intuitiv och a-rationell, estetiska omdömen är meningslösa "metafysiska" (de logiska positivisterna). Estetiska omdömen anses t.ex. endast vara uttryck för känslor och/eller värderingar (s.k. emotivism), vilket betyder att det därmed bara är frågan om ett poänglöst tyckande.

2) som ett slags motreaktion till detta synsätt har man velat påstå, att den estetiska diskursen nog skenbart är icke-rationell, men genom en rationell rekonstruktion kan den bringas i en meningsfull form (dvs. en form som motsvarar kraven på rationalitet - t.ex. ett deduktivt resonemang) (Beardsley, den metakritiska traditionen inom analytisk estetik).

Egentligen är det här frågan om två sidor av samma slant: båda alternativen är förankrade i den positivistiska traditionen, och spelar därför med ett alltför inskränkt rationalitetsbegrepp. Den falska dikotomin uppkommer därför att man anser den filosofiska analysens uppgift vara en kritik av språket, ett uppklarande av otydliga begrepp och tankar. Men om man kan frigöra sig ur en alltför snäv uppfattning av vad rationalitet innebär, är det klart att man kan säga att estetiska omdömen har en egen rationalitet, utan att hävda att estetiska omdömen vore objektiva i samma bemärkelse som vetenskapen traditionellt ansetts vara objektiv (dvs. så att man genom en "analys" kan avgöra huruvida en viss proposition är objektiv eller subjektiv, meningsfull eller "metafysisk"). Detta ideal på verifierbarhet är i praktiken omöjligt att uppnå, och det enda kriteriet på objektivitet såväl inom vetenskapen som på andra områden blir i sista hand en enighet i omdömen.

Motsättningen som ligger under alternativen kan alltså upplösas om man inte godtar den syn på filosofi och rationalitet som båda arbetar med. Artikulationen av den kunskap som ingår i estetiska praxis synes bristfällig bara då man betraktar den ur ett sådant externt perspektiv, som ställer vissa godtyckliga gränser för vad som kan kallas kunskap eller kunnande. Den nyare vetenskapsfilosofin (som i mångt influerats av Wittgenstein) vill betona att även vetenskapen måste ses som en verksamhet eller praxis, och det att det naturvetenskapliga rationalitetsbegreppet spelar sin roll i denna praxis - det finns ingen evig, ahistorisk uppsättning av kriterier för rationalitet som filosofen kan upp- 
täcka och som otvetydigt kan berätta oss vem som är rationell och vem som inte är det. Detta betyder inte att vi måste omfatta någon typ av relativism. Grunder och argument är alltid inbäddade i ett vedertaget bruk med sin egen historia och tradition. För att uppnå korrekt förståelse av mänskliga aktiviteter krävs att man betonar deras egenart. ${ }^{1}$ Den kunskapsform som är aktuell inom den estetiska diskursen sådan som den de facto praktiseras är på inget sătt godtycklig eller i sig problematisk, om den betraktas ur praxisintern synvinkel.

Den estetiska diskursen kan sāgas beskriva en "arena" för kommunikation mellan individer som delar en viss kompetens och bakgrund. Vid en dylik kommunikationssituation ökar metaforerna och analogiernas roll. Fenomenet kan iakttas t.ex. i vardagliga talsituationer. Här är det inte frågan om en deduktion som skulle grunda sig på logiska axiom, vilket inte betyder att det vardagliga talet skulle vara på något sătt "ofullständigt" innan det ōversatts till den logiska kalkylens form. På det estetiska området tillspetsas situationen, eftersom man i Kjell Johannessens efterföljd kan säga, att just den estetiska diskursen präglas av användningen av metaforer, analogier och konkreta exempel. Detta är ju detta diskursens karakteristiska drag, eftersom den kunskap som härvid kommuniceras är av det slaget, att den inte kan överföras på andra sätt. ${ }^{2}$ Kravet på att det estetiska omdömet måste kunna rekonstrueras i form av en logisk deduktion är i själva verket bara en fortsāttning av ett positivistiskt tānkesātt (drōmmen om det exakta och fullständiga språket). Försöken att "översätta" dessa metaforer till logiska axiom eller propositioner i ett "neutralt observationsspråk" eller något slag av idealspråk är dömt att misslyckas, eftersom det inte finns någon neutral, arkimedisk punkt utanför den ifrågavarande praxis. Detta betyder āndå inte att vi är tvungna att acceptera någon form av kritisk singularism, som skulle innebära att man aldrig kan argumentera för estetiska värderingar. De grunder och argument som härvid är relevanta är bara till sin form sådana, att de inte passar in i det positivistiska idealet.

1Dessa tankegångar har sina rötter i Wittgensteins senfilosofi. Inom estetiken har detta "praxisorienterade" synsätt utvecklats särskilt av den s.k. "Bergenskolan" (främst Kjell Johannessen och Tore Nordenstam).

2Se Kjell S. Johannessen 1984, särsk. s. 40-50. 
Estetiska egenskaper är relativa, men detta betyder inte att de vore irrationella eller rent subjektiva. Den analytiska estetiken (åtminstone i Beardsleys form) är just modellerad på den form av vetenskaplig rationalitet som har varit en modell för den dominerande vetenskapsfilosofiska synen. Den postpositivistiska vetenskapsfilosofin har gjort sitt bästa för att upplösa myten om en evig, oföränderlig rationalitet, men denna idé är djupt rotad i vår kultur och lever - ofta omedvetet - kvar (t.ex. inom kognitiv vetenskap och AI-utvecklingsarbete). Estetiska såväl som andra "problem" uppkommer alltid inom en viss tradition, mot en viss bakgrund och vissa behov. Det som måste inses är att den estetiska diskursens bakgrund inte är den, i vars form den positivistiska traditionen vill tvinga vetandet. Ett exempel: om vi betraktar en sådan allmänt giltig estetisk kategori som "harmoni" eller "lämplighet", måste vi konstatera, att vi inte kan hitta objektiva, allmängiltiga kriterier för den. "Lämplighetens" villkor bestämmes inte av "världen" utan av den som ställer kraven. ${ }^{1}$ Här framkommer också de sk. estetiska reaktionernas vikt: att man uppfattar något som harmoniskt betyder inte att man gör ett omdöme som grundar sig på en deduktion på basen av t.ex. icke-estetiska egenskaper. I stället är det frågan om en reaktion "Just så skall det vara". Detta hjälper en också att inse varför konkreta exempel är viktigare än allmänna regler i den estetiska diskursen.

Mer allmänt kan det konstateras, att man inte kan ställa upp generella bruksvillkor för estetiska begrepp; deras användning karakteriseras snarast av en "familjelikhet", inte av nödvändiga och tillräckliga villkor som kan uttryckas i form av entydiga definitioner. ${ }^{2}$ Deras mening bestäms situation för situation i den estetiska diskursen i förhållande till en viss bakgrund. Denna bakgrund i sin tur består inte av abstrakta propositioner, och den kan inte restlöst "rekonstrueras" i denna form. Winograd och Flores konstaterar i sin kritik av AI att försöket till artikulation kan vara nyttigt och viktigt, men den kan aldrig vara täckande. ${ }^{3}$

1Se t.ex. Winograd \& Flores 1986, s. 172.

2Jfr. Weitz' berömda tillämpning av Wittgensteins familjelikhetsidé bla. på begreppet "konst" (Weitz 1977).

3 Estetiken är ett område där frågorna löses genom omdöme snarare än "data" eller skicklighet. Därför är "experterna" på estetiska frågor snarare auktoriteter, och inte experter i den bemärkelse som t.ex. Beardsley vill hävda (se Beardsley 1958, s. 581). 
Om utgångspunkten implicit eller explicit är målsāttningen att producera ett objektivt, bakgrundsfritt språk för datorimplementeringar, måste man begränsa sig till områden där artikulationen för ett givet mål kan vara fullständig (kriteriet för "fullstän dighet" är naturligtvis inte logiskt utan kan bedömas bara från fall till fall). Denna "fullständiga artikulation" är möjlig inom vissa begrānsade områden, som Winograd och Flores kallar systematiska domäner, men inte i andra fall. Därmed kan det hända att ett system i vissa sammanhang drabbas av en fatal "blindhet". Det är just då som frågan om kunskapens "tysthet" aktualiseras.

Slutsatserna angående den "tysta kunskapens" inverkan på ESSU-projektet är naturligtvis beroende av projektets målsättningar. Våra bakgrundsantaganden inverkar medvetet eller omedvetet på vad vi gör, hur vi gör det, och hurudana målsättningar vi ställer upp. Vissa antaganden om kunskapens, tänkandets och språkets natur har en tendens att styra t.ex. diskussionen om datorstödd planering samt om estetikens ställning inom arkitekturen i förhållande till de nya planeringsteknikerna.

Då man betraktar frågor om en estetiskt högklassig miljö och nya planeringstekniker ur ett visst perspektiv förs tankarna sas. automatiskt till idéer om elektroniska expertarkitekter eller - kritiker. För att man skall kunna undvika den "blindhet" som är

inneboende i detta borde saken kunna granskas från en annan synvinkel. Om vi kan byta perspektiv och frigöra oss från den positivistiska synen på estetiska egenskaperoch omdömen innebär detta åtminstone följande för ESSUs del: eftersom vi egentligen inte kan ha "experter" på estetiska frågor (i samma mening vi kan ha experter t.ex. i betongtillverkning), är försōken att utveckla något slag av estetiskt expertsystem ett mål som kanske borde ōverges. Det finns fungerande expertsystem på arkitekturens område, men de fungerar inom väl avgränsade, "systematiska domäner", och det är ett allvarligt felslut att tänka sig att utvecklingen av dessa expertsystem bara är det första steget på vägen mot "Computer Made Design", en elektronisk "expertarkitekt" som kan lösa alla arkitektoniska problem, eller att estetiken vore en dylik "systematisk domän". Misstaget kommer sig av att man kan tänka sig byggnaden som teknisk produkt vara en sådan (om än mycket komplicerad) domän. 
Om vår interaktion med datorn måste pressas in i den trånga mall som bestäms av det formaliserbara området leder detta till svårigheter och en förvrängd syn av problemområdet. Detta är en följd av vad Stuart Shanker kallar det mekanistiska felslutet: vår bristfälliga insikt i den automatiska databehandlingens struktur och möjligheter (det den "egentligen" går ut på) tillsammans med vårt sătt att tala om och tänka på dessa saker (både på vardagsspråket och inom filosofin) för oss vilse. Det mekanistiska felslutet innebär, kort sagt, en sammanblandning av språkspel, som leder till en vrångbild av vad man egentligen försöker och kan åstadkomma. Shanker noterar, att t.ex. det japanska projektet för "femte generationens" datorer, sådant som dess mål beskrivs, är omöjligt pga. begreppsliga missförstånd i denna beskrivning (t.ex. "att få datorer att förstå naturligt språk"). Här anses alltså förståendet var en mekanism.

Detta betyder emellertid inte att projektet $\mathbf{i}$ sig skulle vara dömt att misslyckas: poängen är i stället, att den prosa som används för att göra projektet intelligibelt för allmänheten och beslutsfattarna kan leda hela projektet på villovägar och fördunkla de saker, som verkligen är av vikt i sammanhanget. ${ }^{1}$

På samma sătt, vill jag hävda, kan accepterandet av en positivistiskt influerad estetik ESSU-projektet på villovägar: försök att utveckla "estetiska expertsystem" o.dyl. Däremot kan en "praxisbetonad" estetik ge möjligheter att se hur utvecklingsarbetet skall inriktas. En filosofisk kritik av de begreppsliga misstag som är involverade är nödvändig för att man skall kunna undvika målsättningar som låter äventyrliga, spännande, och möjliga att uppnå, men som i sista hand vilar på missförstånd. Det här är naturligtvis inte hela saken. Om så vore, skulle ju en filosofisk kritik vara tillräcklig. Det viktiga som står på spel är ju trots allt det konkreta utvecklingsarbetet, vars framsteg ingen kan förneka. Men för att få en uppfattning av vad som i själva verket kan åstadkommas, måste vi försöka frigöra oss från de tankar som så att sãga ger sig i sammanhanget, och i stället försöka se saken ur ett nytt perspektiv, som respekterar de olika praxis eller "världarnas" egenart och självständighet.

1Se Shanker 1987, s. 79. 
De problem som uppkommer i samband med "kunskapsrepresentation" inom det estetiska området innebär, att om vi verkligen vill beakta de estetiska aspekterna krävs det en reorientering av sättet att tänka på datorstödda design- och planeringstekniker inom arkitekturen. Den blindhet som finns inbyggd i den dominerande tanketraditionen får inte förhindra de slutsatser denna reorientering kräver. Winograd och Flores påpekar:

The most succesful designs are not those that try to fully model the domain in which they operate, but those that are "in alignment" with the fundamental structure of that domain and that allow for modification and evolution to generate new. structural couplings. ${ }^{1}$

Man bör alltså koncentrera sig på att undersöka arkitekturen och planeringen med utgångspunkt i dem själva, deras traditioner och praxis, utan att tvinga in olika kunskapsformer i en och samma mall. Det gäller att betona formgivarens och kritikerns omdöme och ansvar, inte att flytta över detta på en maskin. Eventuella konflikter som gäller estetiska omdömen kan inte undvikas, men de borde lösas genom en "diskurs" eller dialog, inte genom att hänvisa till vissa formella regler. Det här betyder, att "de nya planeringsteknikerna" borde ses som nya verktyg snarare än någonting som helt och hållet förändrar den arkitektoniska praxisens natur. ${ }^{2}$ Datorstödd planering är i och för sig varken orsaken till eller botemedlet för den degeneration av estetisk kvalitet som dagens bebyggda miljö alltför ofta är ett exempel på.

1Winograd \& Flores 1986, s. 53.

2Detta betyder naturligtvis inte att synen på datorn som instrument eller verktyg vore oproblematisk. 


\section{Bibliografi:}

Beardsley, Monroe 1958: Aesthetics: Problems in the Philosophy of Criticism, New York.

Born, Rainer (ed.) 1987: Artificial Intelligence: the Case Against. London.

Johannessen, Kjell S. 1984: Kunst språk og estetisk praksis. Bergen, Universitetet $\mathbf{i}$ Bergen, Filosofisk institutt.

Shanker, S.G. 1987: "The Decline and Fall of the Mechanist Metaphor", in Born (ed.) 1987.

Weitz, Morris 1977: The Opening Mind. A Philosophical Study of Humanistic Concepts, Chicago.

Winograd, Terry \& Flores, Fernando 1986: Understanding Computers and Cognition: a New Foundation for Design. Norwood, N.J.

Wittgenstein, Ludwig 1969: On Certainty/Über Gewissheit. Ed. G.E.M. Anscombe and G.H von Wright. Oxford. 